\title{
Prolonged mechanical ventilation after cardiac surgery: Outcome and predictors
}

\author{
Jean-Louis Trouillet, $\mathrm{MD},{ }^{\mathrm{a}}$ Alain Combes, $\mathrm{MD}, \mathrm{PhD},{ }^{\mathrm{a}}$ Elisabeth Vaissier, $\mathrm{MD},{ }^{\mathrm{b}}$ Charles-Edouard Luyt, $\mathrm{MD},{ }^{\mathrm{a}}$ \\ Alexandre Ouattara, MD, ${ }^{\mathrm{b}}$ Alain Pavie, $\mathrm{MD}, \mathrm{PhD},{ }^{\mathrm{c}}$ and Jean Chastre, $\mathrm{MD}, \mathrm{PhD}^{\mathrm{a}}$
}

\begin{abstract}
Objective: Prolonged mechanical ventilation after cardiac surgery is a serious complication that warrants search for new treatment strategies. Our objective was to identify patients still requiring mechanical ventilation 3 days after the operation and those successfully weaned by day 10 to avoid needless and potentially hazardous interventions, such as tracheostomy.
\end{abstract}

\begin{abstract}
Methods: All consecutive patients still mechanically ventilated on day 3 after cardiac surgery were included in a prospective observational cohort. Patients' preoperative, intraoperative, and postoperative data were recorded. Logistic regression analysis was used to identify factors associated with successful weaning from mechanical ventilation by postoperative day 10 .
\end{abstract}

Results: Among 2620 patients who underwent cardiac surgery, 163 were still receiving ventilatory assistance on day 3. By day $10,50(31 \%)$ patients had been successfully weaned, $78(48 \%)$ were still receiving mechanical ventilation, and $35(21 \%)$ had died. Multivariable regression analysis retained 6 day-3 factors associated with successful weaning (odds ratio): urine output $500 \mathrm{~mL} / 24$ hours or greater (16.47), Glasgow coma score of 15 (9.75), arterial bicarbonates $20 \mathrm{mmol} / \mathrm{L}$ or greater (6.09), platelet count $100 \mathrm{~g} / \mathrm{L}$ or greater (3.18), patients without inotropic support with epinephrine/norepinephrine (2.84), and absence of lung injury (2.40). The area under the receiver operating characteristics curve for the simple score based on this model's $\beta$-coefficients was 0.84 (95\% confidence intervals, $0.78-0.91$ ). Depending on the threshold chosen for this scoring system, only $3 \%$ to $17 \%$ of the patients would have received a needless intervention.

Conclusions: A simple score based on postoperative day-3 physiologic parameters might help intensivists early identify patients with a strong likelihood of success in rapid weaning from mechanical ventilation and therefore prevent needless procedures aimed at reducing duration of mechanical ventilation and related complications.

Patients undergoing cardiac surgery are generally able to resume spontaneous ventilation as soon as they have recovered from the anesthesia. However, approximately $2.6 \%$ to $22.7 \%$ of them require prolonged mechanical ventilation (MV), depending on the threshold selected to define prolonged MV. ${ }^{1-7}$ For these latter patients, in-hospital mortality can exceed $40 \% .^{7}$ MV duration and length of hospital stay can reach or exceed 2 to 3 weeks, ${ }^{1,4}$ with a major economic impact and consequences on quality of life. ${ }^{5,8}$ In one study, effective cost per survivor was 18 times higher for patients mechanically ventilated for more than 4 days than for weaned patients. ${ }^{3}$ In another study, the extubation-failure group consumed $37 \%$ of patient-days in intensive care unit (ICU) care. ${ }^{9}$

From the Service de Réanimation Médicale, ${ }^{a}$ Département d'Anesthésie Réanimation, ${ }^{\mathrm{b}}$ and Service de Chirurgie Thoracique et Cardiovasculaire Pr Gandjbakhch, Institut de Cardiologie, Hôpital Pitié-Salpêtrière, Assistance Publique-Hôpitaux de Paris, Université Paris 6 Pierre et Marie Curie, Paris, France.

Received for publication Feb 20, 2009; revisions received April 29, 2009; accepted for publication May 31, 2009; available ahead of print July 13, 2009.

Address for reprints: Jean-Louis Trouillet, MD, Réanimation Médicale, Institut de Cardiologie, Hôpital Pitié-Salpêtrière, 47-83 boulevard de l'Hôpital, 75651 Paris

Cedex 13, France (E-mail: jean-louis.trouillet@psl.aphp.fr).

J Thorac Cardiovasc Surg 2009;138:948-53

0022-5223/\$36.00

Copyright (c) 2009 by The American Association for Thoracic Surgery

doi:10.1016/j.jtcvs.2009.05.034
New interventions or treatment strategies are desirable to improve the outcomes of this specific group of patients. For example, early percutaneous tracheotomy, which has been shown to shorten MV duration and lower mortality in patients in the ICU, might be beneficial in such situations. ${ }^{10-13}$

However, ICU physicians' prediction for MV weaning is manifestly inaccurate ${ }^{14}$ and, to date, no clinical test or scoring system has been able to correctly identify patients for whom MV duration will be prolonged and therefore these interventions might be beneficial. Additionally, performing interventions such as tracheostomy in patients with a high probability of rapid and successful weaning might at best be useless and at worst be associated with severe complications. Therefore, the objective of this study was to evaluate patients still receiving MV 3 days after heart surgery. We wanted to identify those with a strong likelihood of rapid MV weaning success, within the 10 postoperative days, to avoid needless interventions aimed at reducing MV duration, such as early tracheostomy.

\section{PATIENTS AND METHODS}

This study was conducted in accordance with the ethical standards of our hospital's Committee for the Protection of Human Subjects. Informed consent was not required because this observational study did not modify existing diagnostic or therapeutic strategies. 


\section{Abbreviations and Acronyms

$\begin{array}{ll}\mathrm{CABG}= & \text { coronary artery bypass graft } \\ \mathrm{ECMO}= & \text { extracorporeal membrane } \\ & \text { oxygenation } \\ \mathrm{FIO}_{2}, & \text { fraction of inspired oxygen } \\ \mathrm{ICU} & =\text { intensive care unit } \\ \mathrm{MV} & =\text { mechanical ventilation } \\ \mathrm{PaO}_{2} & =\text { partial pressure of arterial oxygen } \\ \mathrm{SAPS} \mathrm{II} & =\text { simplified acute physiology score } \\ \text { SOFA score }= & \text { sepsis-related organ failure score }\end{array}$

\section{Study Population}

Between October 2004 and January 2006, all consecutive patients older than 18 years, who had undergone cardiac surgery and were still receiving MV 48 hours later or who had been reintubated before the 96th hour, that is, were on MV on postoperative day 3, were enrolled in this prospective study conducted in a single cardiothoracic surgical ICU in a university hospital.

Patients were excluded from this study (1) if they had died within the first 3 postoperative days, (2) if they required MV more than 48 hours before surgery or mechanical circulatory assistance before surgery, or (3) if an artificial heart (i.e, CardioWest [SynCardia Systems, Inc, Tucson, Ariz] or HeartMate [Thoratec Corporation, Pleasanton, Calif]) was implanted. On the other hand, patients were included if extracorporeal membrane oxygenation (ECMO) was used temporarily after cardiac surgery, including heart transplantation.

\section{ICU Management}

At the end of the operation, patients were admitted directly to the cardiothoracic ICU. Initial hemodynamic management (adequate volume therapy, inotropes, and/or vasopressors) was tailored to patients' status and type of operation. Hemodynamic status was controlled continuously with an arterial catheter for all patients and a pulmonary artery catheter in the case of hemodynamic instability. The patients were ventilated by the volume-assist control mode with a tidal volume of 8 to $10 \mathrm{~mL} / \mathrm{kg}$ predicted body weight. The fraction of inspired oxygen $\left(\mathrm{FiO}_{2}\right)$ and respiratory rate adjustments were made according to routine blood-gas analyses to maintain partial pressure of arterial oxygen $\left(\mathrm{PaO}_{2}\right)$ between 80 and $100 \mathrm{~mm} \mathrm{Hg}$ and partial pressure of arterial carbon between 35 and $40 \mathrm{~mm} \mathrm{Hg}$. Postoperative sedation with sufentanil and midazolam was adjusted to achieve a sedation level at which the patient responds to gentle shaking, corresponding to a Ramsay sedation score of 4 or 3. Patients were tested for tracheal extubation within 6 hours of arrival in the ICU, aiming for systolic blood pressure greater than $100 \mathrm{~mm}$ $\mathrm{Hg}$, pulse rate less than 100 beats/min, and no or low-dose vasoconstrictive drugs. Blood loss had to be less than $100 \mathrm{~mL} / \mathrm{h}$, with a trend toward decreased fluid drainage from chest drains. The decision to extubate a patient was left to the independent discretion of the consulting anesthetist, usually after a trial of spontaneous breathing or a trial under low-level pressure support. However, before extubation, the patient had to be neurologically alert and oriented, able to move equally all four limbs, breathe spontaneously, and obey commands.

\section{Data Collection}

A specific chart was constituted prospectively. Day 1 corresponded to the day of surgery. All of the following parameters were recorded preoperatively: age; sex; body mass index; chronic respiratory insufficiency, defined as maximal expiratory flow volume/second less than $75 \%$ of the theoretical value or continuous treatment with a $\beta 2$ mimetic, corticosteroids, or history of MV; chronic renal insufficiency defined as the need for extrarenal dialysis; diabetes mellitus if the patient was receiving insulin at home; and comorbidity scores, that is, scores devised by McCabe and Jackson ${ }^{15}$ and Charlson and associates ${ }^{16}$; New York Heart Association class; left ventricular ejection fraction less than $50 \%$; European system for cardiac operative risk evaluation (EuroSCORE) ${ }^{17}$; and elective or emergency surgery.

Intraoperative factors were as follows: type of surgery classified in five categories: (1) coronary artery bypass graft (CABG), (2) valve surgery, (3) CABG + valve surgery, (4) transplantation, and (5) miscellaneous (corresponding mainly to aortic dissection or aortic aneurysm and sometimes pericardectomy, myxoma, or ventricular aneurysm); cardiopulmonary bypass and aortic crossclamp times, use of an intra-aortic balloon pump, ECMO use; and troponin I level the day after the operation.

Postoperative parameters recorded on postoperative day 3 were as follows: simplified acute physiology score (SAPS) $\mathrm{II},{ }^{18}$ recording the worst value for the parameters, sepsis-related organ failure (SOFA) score, ${ }^{19}$ and some dichotomized clinical biological and radiologic parameters usually taken into account in scores such as SOFA score or lung injury score and Murthy radiologic score, ${ }^{20}$ with cutoffs corresponding to those routinely reported to describe severe status (ie, Glasgow coma score less than 15 [evaluated for a patient still receiving intravenous sedation or not], lung injury defined by the association of $\mathrm{PaO}_{2} / \mathrm{FIO}_{2}$ ratio less than 200, and radiologic pulmonary abnormalities in at least two quadrants, use of epinephrine or norepinephrine at any dose, oligo-anuria [urine output $<500 \mathrm{~mL} / 24$ hours]; less than $100 \times 10^{9}$ platelets/L, and arterial bicarbonates less than $20 \mathrm{mmol} / \mathrm{L}$. SAPS II on day 3 was also dichotomized according to the median value for the cohort.

The evaluation period was defined as the 7 days after postoperative day 3 (ie, postoperative day 10): the patient was either alive and off MV, defining the successfully weaned group, or MV-dependent or dead, defining the failed-weaning group.

The following outcome parameters were also recorded: MV duration, length of ICU stay, in-hospital mortality, and mortality on postoperative day 30 .

\section{Statistical Analysis}

The analyses compared the group of patients successfully weaned by day 10 with those who either died or remained MV-dependent at postoperative day 10 (failed-weaning group). Results are expressed as the means \pm standard deviation (SD) or $\mathrm{n}(\%)$, as appropriate. All statistical analyses were performed with values available on day 3 . We used the Student $t$ test or the Mann-Whitney $U$ test, when the distribution was not normal, to compare continuous variables, and the $\chi^{2}$ test or Fisher's exact test to compare percentages, as appropriate.

Univariable analysis was used to identify parameters associated with successful MV weaning. Thereafter, a stepwise multivariable logistic regression analysis was used to determine factors independently associated with weaning success, as defined above. Variables were entered into the model when they were associated with the weaning outcome, based on a univariable analysis significance threshold of $P<.10$. Odds ratio and $95 \%$ confidence intervals were calculated. The final model was constructed by backward elimination of nonsignificant variables. The Statistical Package for the Social Sciences (SPSS, version 10.0, Chicago, Ill) was used to analyze data.

Thereafter, to derive a simple practical predictive score, the regression $\beta$ coefficients of each significant factor were rounded to the nearest integer and divided by 2 for simplification. The discriminative performance of this score to predict weaning failure (MV duration $\geq 10$ days or death) was evaluated with receiver operating characteristics curves and quantified by calculating the area under the curve and $95 \%$ confidence intervals. For each score threshold, sensitivity, specificity, positive and negative predictive values, and likelihood ratios were calculated using standard methods.

\section{RESULTS}

A total of 2620 patients underwent cardiac surgery during the study period. Among them, $163(6.2 \%)$ fulfilled study 
entry criteria, as all were still receiving MV 3 days after the operation (Figure 1). Fifty $(30.7 \%)$ of them were successfully weaned and alive on postoperative day 10 ; none of these patients was reintubated up to postoperative day 30 . On day $10,78(48 \%)$ were alive but still supported by MV and 35 $(21 \%)$ had died since day 3. Day-30 and in-hospital mortality were $33 \%$ and $42 \%$, respectively. The baseline characteristics and main outcome information of the study cohort are given in Table 1. Among the 163 patients studied (mean age $64 \pm 15$ years), 26 had undergone CABG, 44 valve surgery, 22 combined CABG + valve surgery, 34 had received a heart transplant, and 37 had benefited from other cardiac and aortic procedures. Although the differences did not reach statistical significance, rates of successful weaning were higher after isolated $\mathrm{CABG}$ or valve surgery than after combined CABG + valve surgery, $35 \%$ and $39 \%$ versus $18 \%$, respectively. Univariable analysis of factors associated with successful weaning is shown in Table 2 . No statistically significant difference existed between the 2 groups regarding preoperative and intraoperative parameters. Alternatively, organ failure and disease severity markers and scores (lung injury, inotropic support, kidney injury, SOFA, and SAPS II) evaluated on postoperative day 3 were significantly less altered in patients successfully weaned on day 10. Last, among the 78 patients still mechanically ventilated on day 10, 46 underwent a percutaneous tracheostomy $(18 \pm 6$ days on average after surgery). Day-30 postoperative mortality tended to be higher for nontracheostomized patients $(34.4 \%$ vs $15.2 \% ; P=.07)$. However, in-hospital mortality rates were not statistically different: $19(41.3 \%)$ of 46 versus $15(46.9 \%)$ of 32 for tracheostomized and nontracheostomized patients, respectively.

Multivariable logistic regression analysis retained the following six independent factors, all recorded on postoperative day 3 and associated with weaning success on day 10 (Table 3): urinary output of $500 \mathrm{~mL} / 24 \mathrm{~h}$ or more, arterial bicarbonates of $20 \mathrm{mmol} / \mathrm{L}$ or more, Glasgow coma score of 15 , platelets count of $100 \mathrm{~g} / \mathrm{L}$ or more, patients without inotropic support with epinephrine or norepinephrine, and absence of lung injury. According to their $\beta$-coefficient values, each variable was allocated points as follows: 3 for urinary output of $500 \mathrm{~mL} / 24 \mathrm{~h}$ or more, 2 for arterial bicarbonate level of $20 \mathrm{mmol} / \mathrm{L}$ or more; 1 for Glasgow coma score of $15 ; 1$ for platelet count of $100 \mathrm{~g} / \mathrm{L}$ or more, 1 for patient without inotropic support with epinephrine or norepinephrine, and 1 for the absence of lung injury. The performance of this scoring system, as assessed by the receiver operating characteristics curve, is shown in Figure 1. The area under the curve was 0.84 (95\% confidence intervals, $0.78-0.91)$. Positive and negative predictive values and likelihood ratios for predicting weaning success by day 10 are reported in Table 4. Successful MV weaning score of 7 points or more yielded optimal sensitivity, specificity, positive and negative predictive values, and overall accuracy:

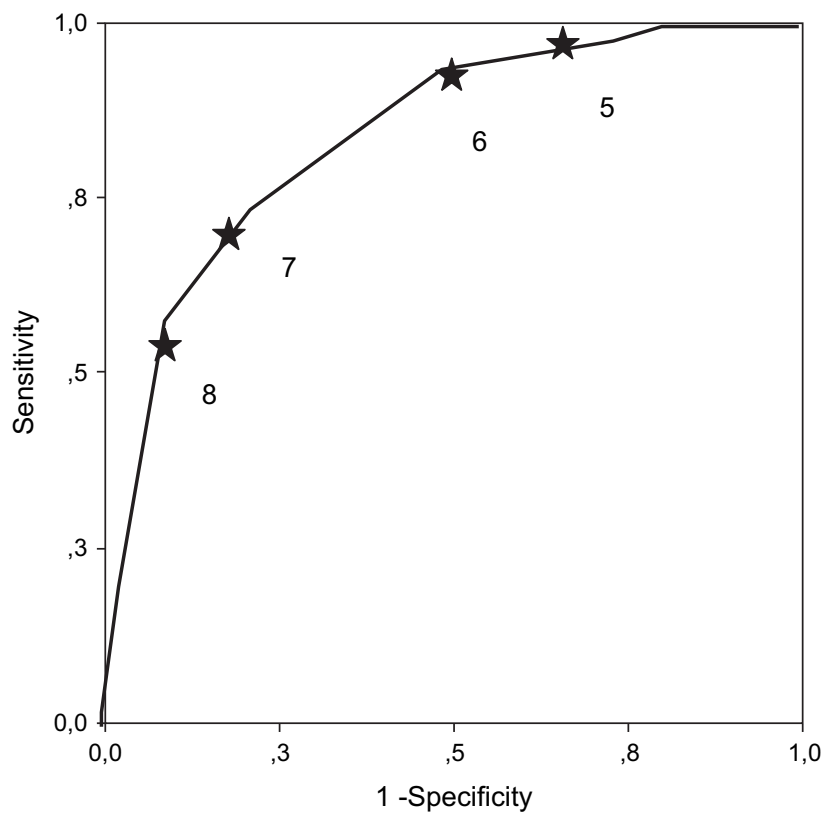

FIGURE 1. Receiver operating characteristics curve for predicting weaning failure with an additive score composed of urinary output of $500 \mathrm{~mL} /$ 24 hours or more ( 3 points) + arterial bicarbonate level of $20 \mathrm{mmol} / \mathrm{L}$ or more $(2$ points $)+$ Glasgow coma score of 15 ( 1 point $)+$ platelet count of $100 \mathrm{~g} / \mathrm{L}$ or more $(1$ point $),+$ no epinephrine or norepinephrine $(1$ point $)+$ no lung injury (1 point). Stars with numbers to the right correspond to different score thresholds. All score parameters were recorded on day 3 after cardiac surgery.

$74 \%, 79 \%, 61 \%, 87 \%$, and $77 \%$. With this scoring system, a needless tracheostomy would have been performed for only $3 \%, 5 \%, 13 \%$, and $17 \%$ of patients whose total score was less than $5,6,7$, and 8 , respectively.

\section{DISCUSSION}

Prolonged MV and ICU stays after cardiac operations are becoming more and more common, as patients referred for heart surgery have ever poorer risk profiles with more

TABLE 1. Characteristics of $\mathbf{1 6 3}$ study cohort patients requiring MV on day 3 after cardiac surgery

\begin{tabular}{lc}
\hline \multicolumn{1}{c}{ Characteristics } & \multicolumn{1}{c}{ Value* } \\
\hline Age (y) & $63.97 \pm 14.99$ \\
Sex (male/female) & $109(66.9) / 54(33.1)$ \\
CABG & $26(16)$ \\
Valve surgery & $44(27)$ \\
Valve surgery + CABG & $22(13.5)$ \\
Heart transplantation & $34(20.9)$ \\
Miscellaneous $\dagger$ & $37(22.7)$ \\
Duration of MV (d) & $20.03 \pm 25.03$ \\
ICU length of stay (d) & $23.19 \pm 25.41$ \\
Postoperative mortality (day 30) & $53(32.5)$ \\
In-hospital mortality & $69(42.3)$ \\
\hline
\end{tabular}

$M V$, Mechanical ventilation; $C A B G$, coronary artery bypass graft. *Values are expressed as means $\pm \mathrm{SD}$ or $\mathrm{n}(\%)$. $\dagger$ Miscellaneous cardiac surgery includes such procedures as repair of aortic dissection, repair of aneurysm rupture, and pericardiectomy. 
TABLE 2. Characteristics of the 163 studied patients according to weaning outcome on day 10 after cardiac surgery

\begin{tabular}{|c|c|c|c|}
\hline Variables & Successful weaning $(n=50)$ & Unsuccessful weaning* $(n=113)$ & $P$ value \\
\hline \multicolumn{4}{|l|}{ Preoperative } \\
\hline Age $(y)$ & $62.8 \pm 15.8 \dagger$ & $64.5 \pm 14.7$ & .50 \\
\hline Male sex & $34(68)$ & $75(66.4)$ & .83 \\
\hline Body mass index & $26.3 \pm 17.4$ & $24.9 \pm 22.5$ & .09 \\
\hline Charlson comorbidity index & $2.2 \pm 1.9$ & $2.6 \pm 2.2$ & .27 \\
\hline McCabe/Jackson score 3 & $40(80)$ & $90(79.6)$ & .96 \\
\hline NYHA class III-IV & $31(62)$ & $68(60.2)$ & .83 \\
\hline Chronic respiratory failure & $9(18)$ & $12(10.6)$ & .21 \\
\hline Chronic renal failure & $1(2)$ & $6(5.3)$ & .67 \\
\hline Diabetes mellitus & $3(6)$ & $12(10.6)$ & .55 \\
\hline LVEF $<50 \%$ & $29(58)$ & $53(46.9)$ & .19 \\
\hline EuroSCORE & $7.4 \pm 4.7$ & $7.4 \pm 3.3$ & .98 \\
\hline Emergency surgery & $28(56)$ & $56(50)$ & .44 \\
\hline \multicolumn{4}{|l|}{ Intraoperative variables } \\
\hline \multicolumn{4}{|l|}{ Type of heart surgery } \\
\hline CABG surgery & $9(18)$ & $17(15)$ & .63 \\
\hline Valve surgery & $17(34)$ & $27(24)$ & .18 \\
\hline $\mathrm{CABG}+$ valve surgery & $4(8)$ & $18(16)$ & .17 \\
\hline Heart transplantation & $12(24)$ & $22(19)$ & .51 \\
\hline Other heart surgery procedures & $8(16)$ & $29(26)$ & .17 \\
\hline Duration of $\mathrm{CPB}(\mathrm{min})$ & $107 \pm 49$ & $119 \pm 62$ & .22 \\
\hline Aortic crossclamp time (min) & $74 \pm 49$ & $84 \pm 49$ & .2 \\
\hline Intra-aortic balloon pump & $4(8)$ & $11(9.7)$ & .99 \\
\hline Postoperative ECMO & $3(6)$ & $19(16.8)$ & .08 \\
\hline Troponin I day $2(\mathrm{mg} / \mathrm{L})$ & $14.7 \pm 24.5$ & $21 \pm 33.9$ & .28 \\
\hline \multicolumn{4}{|l|}{ Postoperative day 3} \\
\hline SAPS II $\dagger$ & $37.52 \pm 8.65$ & $49.66 \pm 14.03$ & $<.0001$ \\
\hline SAPS II $\geq 45 \ddagger$ & $10(20)$ & $65(57.5)$ & $<.0001$ \\
\hline SOFA $\dagger$ & $8.96 \pm 3.01$ & $11.62 \pm 2.98$ & $<.0001$ \\
\hline Glasgow coma score $<15$ & $4(8)$ & $31(27.4)$ & .006 \\
\hline Lung injury§ & $19(38)$ & $59(52.2)$ & .09 \\
\hline Epinephrine or norepinephrine & $34(68)$ & $95(84)$ & .04 \\
\hline Urinary output $<500 \mathrm{~mL} / 24 \mathrm{~h}$ & $1(2)$ & $27(23.9)$ & .0002 \\
\hline Arterial bicarbonates $<20 \mathrm{mmol} / \mathrm{L}$ & $22(44)$ & $91(80.5)$ & $<.0001$ \\
\hline Platelet count $<100 \times 10^{9} / \mathrm{L}$ & $19(38)$ & $66(58.4)$ & .02 \\
\hline \multicolumn{4}{|l|}{ Outcome measure } \\
\hline MV duration (d) & $5.4 \pm 2.5$ & $26.5 \pm 27.7$ & $<.0001$ \\
\hline ICU stay (d) & $11.4 \pm 7.2$ & $28.3 \pm 28.6$ & .0008 \\
\hline Hospital stay (d) & $29.2 \pm 14.3$ & $34.6 \pm 31.8$ & .25 \\
\hline In-hospital mortality & 0 & $69(61)$ & $<.0001$ \\
\hline
\end{tabular}

NYHA, New York Heart Association; $L V E F$, Left ventricular ejection fraction; EuroSCORE, European System for Cardiac Operative Risks Evaluation; $C A B G$, coronary artery graft bypass; $C P B$, cardiopulmonary bypass; $E C M O$, extracorporeal membrane oxygenation; $S A P S$, simplified acute physiology score; $S O F A$, sepsis-related organ failure score; $M V$, mechanical ventilation; $I C U$, intensive care unit. *Defined as death or persistent mechanical ventilation on day 10 after cardiac surgery. $\nmid$ Values are expressed as means \pm SD or (\%). $\ddagger$ Cutoff value corresponding to the mean. $\S$ Defined as the combination of $\mathrm{PaO}_{2} / \mathrm{FIO}_{2}$ ratio $<200$ and presence of radiologic abnormalities in at least 2 quadrants.

comorbidities. Our $6.2 \%$ rate of patients requiring MV for more than 72 hours is close to the rates reported in other recent series, ranging between $3.2 \%$ and $9.1 \% .^{3,21,22}$ This group of very sick patients has considerably higher mortality rates than patients rapidly weaned from MV. Thirty-day mortality was $24 \%$ in a study by Murthy and associates ${ }^{22}$ and was even higher in our patients $(33 \%)$, although remaining in the range of that predicted from SAPS II and SOFA scores calculated on postoperative day 3 . Thus, implementation of specific strategies and interventions to improve the outcomes of this specific subset of patients is urgently needed.
Our main objective when designing the present study was to define an algorithm that might accurately select early on postoperative day 3 , patients who would be successfully extubated by day 10 . Indeed, while patients with high probabilities of prolonged MV might benefit most from interventions such as early tracheostomy, this type of procedure might be at best useless or even sometimes dangerous in patients experiencing rapid and successful MV weaning. Several studies have investigated factors associated with prolonged MV after cardiac surgery..$^{2-6,9,21-34}$ Serrano and associates $^{33}$ reported on a series of 569 patients undergoing 
TABLE 3. Multivariable logistic regression analysis: Factors associated with postoperative day-10MV weaning success

\begin{tabular}{lclc}
\hline \multicolumn{1}{c}{ Variables } & Odds ratio & $\mathbf{9 5} \%$ CI & $\boldsymbol{P}$ value \\
\hline Urinary output $\geq 500 \mathrm{~mL} / 24 \mathrm{~h}$ & 16.47 & $1.87-145.09$ & .01 \\
Glasgow coma score $=15$ & 9.75 & $2.49-38.23$ & .001 \\
Arterial bicarbonates $\geq 20 \mathrm{mmol} / \mathrm{L}$ & 6.09 & $2.54-14.57$ & $<.0001$ \\
Platelets count $\geq 100 \mathrm{~g} / \mathrm{L}$ & 3.18 & $1.29-7.77$ & .01 \\
No epinephrine or norepinephrine use & 2.84 & $1.05-7.68$ & .04 \\
No lung injury & 2.40 & $1.01-5.70$ & .05 \\
\hline
\end{tabular}

$M V$, Mechanical ventilation; $C I$, confidence intervals.

CABG surgery and tested the ability of the Intensive Care Unit Risk Stratification Score (ICURSS) model to predict prolonged MV. However, discrimination and calibration of this scoring system, gathering only preoperative and immediately postoperative variables, were poor. Alternatively, Murthy and colleagues ${ }^{22}$ showed that hemodynamic status on ICU admission (low cardiac output, vasopressor use, pulmonary hypertension) and early postoperative events (stroke, bacteremia) were more important than preoperative and intraoperative variables in predicting ventilatory dependency, defined as MV greater than 72 hours after cardiac operation. A similar observation was reported by Kern and colleagues, ${ }^{3}$ who found that only the postoperative measure of severity of illness by the SAPS II and of the intensity of treatment and nursing care activity by the Therapeutic Intervention Scoring System (TISS) resulted in an effective model for prediction of MV greater than 48 hours. Importantly, our objective differed significantly from these studies, inasmuch as we intended to predict ventilator weaning within 10 postoperative days. Our data confirm that evolution of patients' condition and response to treatment during the first 3 days of MV provide more valuable prognostic input than information collected preoperatively or on postoperative day 1. Furthermore, our simple algorithm might help physicians decide which patients should be targeted for specific interventions aimed at reducing MV duration, such as tracheostomy. Depending on the threshold chosen for this scoring system, only $3 \%$ to $17 \%$ of the patients considered at risk of long-term MV would have been tracheostomized and weaned from MV before day 10 (false negative).

Indeed, tracheostomy has recognized advantages over translaryngeal intubation, such as decreased airway resistance, absence of oral-labial ulcerations, easier oral hygiene or bronchopulmonary toilet, and improvement of airway security. Moreover, our group ${ }^{10}$ has demonstrated that tracheostomy led to less sedative administration, less time spent heavily sedated, enhanced patient mobility, and ability to be fed orally. $\mathrm{We}^{11}$ also reported on a large series of 506 patients requiring prolonged MV, of whom 166 were tracheostomized, that the intervention was associated with lower ICU and in-hospital mortality rates. These observations led us to design the Early percutaneous TracheOstomy for Cardiac surgery (ETOC) trial (http://clinicaltrial.gov), a randomized study comparing early (day 4) versus late (after day 15) tracheostomy for patients still requiring MV 3 days after cardiac surgery, which is currently under way. However, since the benefit of early tracheostomy for long-term postoperative MV patients has not yet been proven, this procedure cannot be systematically recommended for such patients.

\section{Limitations of the Study}

This study has several limitations. First, results of our monocentric study may not be applicable to other centers and the scoring system we designed should be prospectively validated on other groups of patients from other institutions. Indeed, our tertiary referral ICU routinely cares for severely ill patients with terminal cardiac insufficiency, cardiogenic shock, and emergencies like aortic dissection. As also recently demonstrated by Filsoufi and associates, ${ }^{21}$ patients undergoing complex operations such as aortic and combined valve + CABG procedures are the most likely to experience respiratory failure, defined as needing MV for more than 72 hours. Second, we included in our series 22 patients requiring ECMO for refractory cardiogenic shock after cardiac surgery and specifically after heart transplantation. However, these patients were still ventilator-dependent on postoperative day 3, and although ECMO support lasted less than 10 days on average, their mean duration of endotracheal intubation was $31 \pm 28$ days. Third, we may have missed other important factors that may be associated with MV weaning outcome. For example, our database does not contain day-3 echocardiography findings, but use of catecholamine can be considered as a surrogate of cardiovascular dysfunction. Ventilation parameters like tidal volume, $\mathrm{FIO}_{2}$, and positive end-expiratory pressure were also not included in our database, but $\mathrm{PaO}_{2} / \mathrm{FIO}_{2}$ ratio can be

TABLE 4. Operational values of a score* to predict mechanical ventilation success on day 10 after cardiac surgery

\begin{tabular}{lcccccc}
\hline & & & & \multicolumn{2}{c}{ Likelihood ratio } \\
\cline { 3 - 7 } Point threshold & Sensitivity (\%) & Specificity (\%) & PPV (\%) & NPV (\%) & Positive (95\% CI) & Negative (95\% CI) \\
$\geq 8$ & 58 & 91 & 74 & 83 & $6.56(3.64-12.05)$ & $0.46(0.36-0.60)$ \\
$\geq 7$ & 74 & 79 & 61 & 87 & $3.48(2.43-4.76)$ & $0.33(0.21-0.50)$ \\
$\geq 6$ & 94 & 51 & 46 & 95 & $1.93(1.62-2.09)$ & $0.12(0.04-0.32)$ \\
$\geq 5$ & 98 & 27 & 37 & 97 & $1.33(1.18-1.37)$ & $0.08(0.01-0.40)$ \\
\hline$P P V, P o$
\end{tabular}

$P P V$, Positive predictive value; $N P V$, negative predictive value; $C I$, confidence intervals. *Score based on six independent variables: urinary output, Glasgow coma score, arterial bicarbonates, platelets count; epinephrine or norepinephrine, and lung injury (Table 3). 
considered as a relevant marker of respiratory status. Last, inasmuch as the main purpose of this scoring system was to help physicians avoid performing a needless tracheostomy in patients rapidly weaned, we defined the MV weaning-failure group as patients either deceased or still requiring MV by postoperative day 10 , potentially leading to tracheostomizing patients who would die shortly after the procedure. However, because this intervention might have an impact both on survival and on MV duration, such a composite end point might be fully appropriate, as also recently underlined by Gajic and associates. ${ }^{35}$

In summary, patients still requiring MV on day 3 after cardiac surgery had poor outcomes. Only $30 \%$ were successfully weaned on postoperative day 10 . Specific strategies aimed at reducing MV duration and related complications should be tested to improve the outcomes of this subset of critically ill patients. The simple score we propose herein might help physicians better identify patients with a strong likelihood of rapid and successful MV weaning, to avoid needless and potentially hazardous interventions, such as early percutaneous tracheostomy. For other patients, tracheostomy might be an option, since, to date, equipoise exists regarding performing or not this procedure.

We thank Agnès Gaubert for data collection and excellent technical assistance.

\section{References}

1. Kollef MH, Wragge T, Pasque T. Determinants of mortality and multiorgan dysfunction in cardiac surgery patients requiring prolonged mechanical ventilation. Chest. 1995; 107:1395-401.

2. Thompson MJ, Elton RA, Mankad PA, Campanella C, Walker WS, Sang CT, et al. Prediction of requirement for, and outcome of, prolonged mechanical ventilation following cardiac surgery. Cardiovasc Surg. 1997;5:376-81.

3. Kern H, Redlich U, Hotz H, von Heymann C, Grosse J, Konertz W, et al. Risk factors for prolonged ventilation after cardiac surgery using APACHE II, SAPS II, and TISS: comparison of three different models. Intensive Care Med. 2001; 27:407-15.

4. Branca P, McGaw P, Light RW. Risk factors associated with prolonged mechanical ventilation following coronary artery bypass surgery. Chest. 2001;119: 537-46.

5. Rajakaruna C, Rogers CA, Angelini GD, Ascione R. Risk factors for and economic implications of prolonged ventilation after cardiac surgery. J Thorac Cardiovasc Surg. 2005;130:1270-7.

6. Reddy S, Grayson AD, Griffiths EM, Pullan DM, Rashid A. Logistic risk model for prolonged ventilation after adult cardiac surgery. Ann Thorac Surg. 2007;84:528-36.

7. LoCicero J 3rd, McCann B, Massad M, Joob AW. Prolonged ventilatory support after open-heart surgery. Crit Care Med. 1992;20:990-2.

8. Combes A, Costa MA, Trouillet JL, Baudot J, Mokhtari M, Gibert C, et al. Morbidity, mortality, and quality-of-life outcomes of patients requiring $\geq 14$ days of mechanical ventilation. Crit Care Med. 2003;31:1373-81.

9. Rady MY, Ryan T. Perioperative predictors of extubation failure and the effect on clinical outcome after cardiac surgery. Crit Care Med. 1999;27:340-7.

10. Nieszkowska A, Combes A, Luyt CE, Ksibi H, Trouillet JL, Gibert C, et al. Impact of tracheostomy on sedative administration, sedation level, and comfort of mechanically ventilated intensive care unit patients. Crit Care Med. 2005;33:2527-33.

11. Combes A, Luyt CE, Nieszkowska A, Trouillet JL, Gibert C, Chastre J. Is tracheostomy associated with better outcomes for patients requiring long-term mechanical ventilation? Crit Care Med. 2007;35:802-7.

12. Rumbak MJ, Newton M, Truncale T, Schwartz SW, Adams TW, Hazard PB. A prospective, randomized, study comparing early percutaneous dilational tracheos- tomy to prolonged translaryngeal intubation (delayed tracheostomy) in critically ill medical patients. Crit Care Med. 2004;32:1689-94.

13. Gatti G, Cardu G, Bentini C, Pacilli P, Pugliese P. Weaning from ventilator after cardiac operation using the Ciaglia percutaneous tracheostomy. Eur J Cardiothoracic Surg. 2004;25:541-7.

14. Affessa B, Hogans L, Murphy R. Predicting 3-day and 7-day outcomes of weaning from mechanical ventilation. Chest. 1999;116:456-61.

15. McCabe WR, Jackson GG. Gram-negative bacteremia. Arch Intern Med. 1962; 110:847-64

16. Charlson ME, Pompei P, Ales KL, MacKenzie CR. A new method of classifying prognostic comorbidity in longitudinal studies: development and validation. $J$ Chron Dis. 1987;40:378-83.

17. Nashef SA, Roques F, Michel P, Gauducheau E, Lemeshow S, Salamon R. The EuroSCORE study group. European system for cardiac operative risk evaluation (EuroSCORE). Eur J Cardiothorac Surg. 1999;16:9-13.

18. Le Gall JR, Lemeshow S, Saulnier F. A new simplified acute physiology score (SAPS II) based on European/North American multicenter study. JAMA. 1993; 270:2957-63.

19. Vincent JL, Moreno R, Takala J, Willatts S, De Mendonca A, Bruining H. The SOFA (sepsis-related organ failure assessment) score to describe organ dysfunction/failure. Intensive Care Med. 1996;22:707-10.

20. Murray J, Matthay M, Luce J, Flick MR. An expanded definition of the adult respiratory distress syndrome. Am Rev Respir Dis. 1988;138:720-3.

21. Filsoufi F, Rahmanian PB, Castillo JG, Chikwe J, Adams DH. Predictors and early and late outcomes of respiratory failure in contemporary cardiac surgery. Chest. 2008;133:713-21.

22. Murthy SC, Arroligra A, Walts P, Feng J, Yared JP, Lytle BW, et al. Ventilatory dependency after cardiovascular surgery. J Thorac Cardiovasc Surg. 2007;134: 484-90.

23. Bando K, Sun K, Binford RS, Sharp TG. Determinants of longer duration of endotracheal intubation after adult cardiac operations. Ann Thorac Surg. 1997;63: 1026-33.

24. Wong DT, Cheng DC, Kustra R, Tibshirani R, Karski J, Carroll-Munro J, et al. Risk factors of delayed extubation, prolonged length of stay in the intensive care unit, and mortality in patients undergoing coronary artery bypass graft with fast-track cardiac anesthesia: a new cardiac risk score. Anesthesiology. 1999;9:911-5.

25. Suematsu Y, Sato H, Ohtsuka T, Kotsuka Y, Araki S, Takamoto S. Predictive risk factors for delayed extubation in patients undergoing coronary artery bypass grafting. Heart Vessels. 2000;15:214-20.

26. Walthall H, Robson D, Ray S. Do any preoperative variables affect extubation time after coronary artery bypass graft surgery? Heart Lung. 2001;30: 216-24.

27. Légaré JF, Hirsch GM, Buth KJ, MacDougall C, Sullivan JA. Preoperative prediction of prolonged mechanical ventilation following coronary artery bypass grafting. Eur J Cardiothorac Surg. 2001;20:930-6.

28. Yende S, Wunderink R. Validity of scoring systems to predict risk of prolonged mechanical ventilation after coronary artery bypass graft surgery. Chest. 2002; 122:239-44.

29. Ip P, Chiu C, Cheung C. Risk factors prolonging ventilation in young children after cardiac surgery: impact of noninfectious pulmonary complications. Pediatr Crit Care Med. 2002;3:269-74.

30. Dunning J, Au J, Kalkat M, Levine A. A validated rule for predicting patients who require prolonged ventilation post cardiac surgery. Eur J Cardiothorac Surg. 2003;24:270-6.

31. Canver CC, Chanda J. Intraoperative and postoperative risk factors for respiratory failure after coronary bypass. Ann Thorac Surg. 2003;75:853-8.

32. Nakasuji M, Matsushita M, Asada A. Risk factors for prolonged ICU stay in patients following coronary artery bypass grafting with a long duration of cardiopulmonary bypass. J Anesth. 2005;19:118-23.

33. Serrano N, Garcia C, Villegas J, Huidobro S, Henry CC, Santacreu R, et al. for the Epidemiological Project for ICU Research and Evaluation (EPICURE). Prolonged intubation rates after coronary artery bypass surgery and ICU risk stratification score. Chest. 2005;128:595-601.

34. Nozawa E, Azeka E, Ignêz ZM, Feltrim Z, Auler Júnior JO. Factors associated with failure of weaning from long-term mechanical ventilation after cardiac surgery. Int Heart J. 2005;46:819-31.

35. Gajic O, Afessa B, Thompson BT, Frutos-Vivar F, Malinchoc M, Rubenfeld GD et al. Prediction of death and prolonged mechanical ventilation in acute lung injury. Crit Care. 2007;11:R 53. 